\title{
Estilos individuais de aprendizagem e atitude empreendedora: estabelecendo relações entre os construtos
}

\author{
Individual Styles of Learning and Entrepreneurial Attitude: Establishing \\ Relationships between the Constructs
}

\author{
Jefferson Menezes de Oliveira ${ }^{1}$ \\ Vania de Fátima Barros Estivalete ${ }^{2}$ \\ Jaime Peixoto Stecca ${ }^{3}$ \\ Italo Fernando Minello ${ }^{4}$
}

\begin{abstract}
Resumo
O presente estudo teve o objetivo de avaliar o modo como os trabalhadores do setor público aprendem, de forma a identificar os estilos de aprendizagem predominantes, bem como suas relações com a atitude empreendedora. O contexto explorado - uma organização pública - é justificado pelo entendimento de que o empreendedorismo pode ser fundamental para o oferecimento dos níveis de qualidade desejados pela sociedade, podendo contribuir com soluções inovadoras para problemas de ordem pública. Quanto ao método, conduziu-se o estudo com caráter descritivo e quantitativo, sendo que foram aplicados os instrumentos Inventário de estilos de aprendizagem (Kolb, 1976) e Instrumento de Medida de Atitude Empreendedora - IMAE (Souza \& Lopez Jr., 2005) com servidores públicos lotados na unidade de gestão de pessoas de uma instituição federal de ensino localizada na região Sul do Brasil. Os resultados apontaram que, na amostra pesquisada, o estilo de aprendizagem individual predominante é o Convergente, seguido pelos estilos Assimilador e Acomodador. Por meio das análises, o Convergente foi sinalizado como estilo mais inclinado à atitude empreendedora nas quatro dimensões do IMAE. Novos métodos de seleção e alocação de pessoal, bem como a escolha de chefias, poderão ser desenvolvidos a partir dos resultados de pesquisas como esta.
\end{abstract}

Palavras-chave: Aprendizagem; Atitude empreendedora; Organização pública.

\begin{abstract}
This study aimed to evaluate the way in which public sector workers learn, in order to identify the predominant learning styles, as well as their relations with the entrepreneurial attitude. The explored context - a public organization - is justified by the understanding that entrepreneurship can be fundamental to the achievement of the desired levels of quality by society and can contribute with innovative solutions to problems of public order.In relation to the method, the study was conducted with descriptive and quantitative character, and the instruments Learning Style Inventory (Kolb, 1976) and Instrument of Measurement of Entrepreneurial Attitude - IMAE (Souza \& Lopez Jr., 2005) were applied to public servants of a people management unit
\end{abstract}

Possui Graduação em Administração pela Universidade Federal de Santa Maria (UFSM), Especialização em Gestão Pública pela Universidade Federal do Rio Grande do Sul (UFRGS) e Mestrado em Gestão de Organizações Públicas pela Universidade Federal de Santa Maria (UFSM). Atualmente, cursa Doutorado em Administração no Programa de Pós-Graduação em Administração da Universidade Federal de Santa Maria (PPGA/UFSM), na linha de pesquisa Gestão de Pessoas e Comportamento Organizacional. Afiliação: Universidade Federal de Santa Maria. Email: jeffersonmenezes@gmail.com

2 Possui Graduação em Administração pela Universidade Federal de Santa Maria (1986), Mestrado em Engenharia de Produção pela Universidade Federal de Santa Maria (1997), Doutorado em Agronegócios pela Universidade Federal do Rio Grande do Sul (2007) e Pósdoutorado em Sociologia Econômica das Organizações no SOCIUS - Centro de Investigação em Sociologia Económica e das Organizações no ISEG - Instituto Superior de Economia e Gestão da Universidade de Lisboa-Portugal (2015). Professora do Departamento de Ciências Administrativos da Universidade Federal de Santa Maria - UFSM. Afiliação: Universidade Federal de Santa Maria. Email: vaniaestivalete@ufsm. br

Possui Graduação em Administração e Especialização em Gestão Empresarial pela UFSM, Mestrado em Administração pela UFSC e Doutorado em Administração pela FEA/USP. É Professor Federal de Ensino Básico, Técnico e Tecnológico no Colégio Politécnico da UFSM. Afiliação: Universidade Federal de Santa Maria. Email: jeffersonmenezes@gmail.com

4 Possui graduação em Administração de Empresas pela Universidade Federal de Santa Maria - UFSM, especialista em Recursos Humanos pela Fundação para o Desenvolvimento de Recursos Humanos - FDRH (1990) e em Marketing pela Escola Superior de Propaganda e Marketing - ESPM (1991), mestrado em Administração pela Universidade Federal de Santa Catarina - UFSC (1998) e doutorado em Administração pela Faculdade de Economia, Administração e Contabilidade da Universidade de São Paulo - FEA-USP (2010). Atualmente é professor adjunto do Departamento de Ciências Administrativas da UFSM. Afiliação: Universidade Federal de Santa Maria. Email: jeffersonmenezes@gmail.com 
of a federal teaching institution located in the southern region of Brazil. The results showed that, in the sample studied, the predominant individual learning style is the Convergent, followed by the Assimilator and Accommodator styles. Through the analysis, the Convergent was signaled as a style more inclined to the entrepreneurial attitude in the four dimensions of the IMAE. New methods of selection and allocation of personnel, as well as the choice of managers, could be developed from the results of researches like this one.

Keywords: Learning; Entrepreneurial attitude; Public organization.

\section{Introdução}

Em reação aos efeitos da globalização, reavivam-se discussões sobre o empreendedorismo nas organizações. Com maior ênfase, na atualidade, demanda-se por condutas de gestão mais flexíveis e inovadoras, uma vez que a capacidade de identificar e explorar oportunidades pode fomentar o desempenho da organização, introduzindo novos e melhores produtos, serviços ou processos de trabalho (Jong, Parker, Wennekers \& Wu, 2015). Nota-se, em sintonia, o incremento de publicações e pesquisas que contribuem para a compreensão do tema e apontam novas perspectivas de análise (Feger, Fischer \& Nodari, 2010; Valadares \& Emmendoerfer, 2015).

No contexto das organizações públicas, uma dessas novas perspectivas, o empreendedorismo, pode ser fundamental para o oferecimento dos níveis de qualidade desejados pela sociedade. Para tanto, os gestores públicos necessitam propiciar um ambiente organizacional favorável ao comportamento empreendedor (Tinoco, 2012).

Sob o estigma de que os servidores públicos são incapazes de aprender, inflexíveis, sem imaginação e estagnados (Goodsell, 2003), o desenvolvimento da Nova Administração Pública - NAP (New Public Management - NPM) veio aguçar a busca por soluções inovadoras para problemas de ordem pública, pautando-se em maior exposição ao risco, flexibilidade e aprendizado. A NAP intensificou a ênfase na qualidade do serviço público e induziu essas organizações a explorar novas soluções para problemas de eficiência e eficácia (Windrum, 2008). Essas novas demandas, juntamente com as crescentes pressões orçamentárias, incitam os gestores públicos a adotarem novas práticas oriundas, muitas vezes, de outros setores econômicos (Townsend, 2013).

Tais transformações demandam que organizações públicas, portanto, tornem-se mais adaptáveis, pautadas em inovação e em contínua aprendizagem. Presume-se que um ambiente organizacional propício ao aprendizado possibilita que as organizações se posicionem estrategicamente em diferentes momentos (Estivalete, Löbler \& Pedrozo, 2006).

Considerando que as organizações aprendem por meio de seus membros individuais (Kim, 1993), concebe-se que a compreensão do processo de atitude empreendedora pode estar relacionada com o modo como os indivíduos aprendem. Segundo Kolb (1997), o indivíduo se distingue pela capacidade de se adaptar e fazer frente às exigências dinâmicas de seu trabalho e carreira profissional, ou seja, pela capacidade de aprender, a qual é considerada uma característica dos indivíduos empreendedores na visão de Filion (1991).

Desperta-se, assim, para uma investigação que clarifique o modo como os trabalhadores do setor público aprendem, de forma a identificar os estilos de aprendizagem predominantes, bem como suas relações com a atitude empreendedora. A partir desse contexto, o presente artigo busca responder ao seguinte questionamento: De que forma se estabelece a relação entre os estilos de aprendizagem individual e a atitude empreendedora em uma organização pública?

Por escopo, o estudo pretende avaliar essas temáticas com servidores públicos, das áreas técnica e administrativa, lotados na unidade de gestão de pessoas de uma universidade pública brasileira. Organizações dessa natureza são dotadas de peculiaridades no que diz respeito a formas de hierarquia, progressão funcional, ingresso e estabilidade, as quais instigam e desafiam a investigação acerca da atitude empreendedora de seus trabalhadores. Sendo assim, justifica-se o presente estudo pela abordagem do empreendedorismo no serviço público, bem como pela associação da atitude empreendedora com o modo como os trabalhadores desse setor aprendem, um contexto interacional inexplorado. 


\section{Fundamentação Teórica}

Esta seção tem por intuito apresentar a fundamentação teórica acerca das temáticas pesquisadas. Enquanto sua primeira subseção aborda os estilos de aprendizagem individual, a segunda traz concepções sobre a atitude empreendedora, sobretudo a respeito de seus instrumentos de medida.

\subsection{Estilos de Aprendizagem Individual}

Ao se tratar de aprendizagem no contexto das organizações, percebe-se uma tendência de se concentrar no coletivo (organizacional). Portanto, cabe realçar que também não se pode perder de vista a importância do estudo da aprendizagem em nível individual (Bitencourt e Souza, 2003). A qualidade das aprendizagens, individual e coletiva, é determinante para o sucesso da organização (Hayes \& Allinson, 1998).

Contribuindo com esse entendimento, Kim (1993) e Argyris e Schön (1996) compartilham da ideia de que as organizações aprendem através dos indivíduos. Kim (1993) destaca a relevância da aprendizagem individual para a aprendizagem organizacional ao enfatizar que as organizações, ainda que sejam compostas por indivíduos, podem aprender, independentemente de um sujeito específico, mas nunca independentemente de todos. Argyris e Schön (1996) também compartilham da concepção de que os indivíduos são considerados agentes para a aprendizagem nas organizações, no entanto observam que as organizações não devem ser consideradas como uma mera coleção de indivíduos.

Trazendo essa discussão para o nível individual, acrescenta-se a contribuição de Hayes e Allinson (1998), os quais mencionam que o estilo cognitivo, assim como o estilo de aprendizagem, pode exercer influência sobre a forma como os indivíduos da organização processam as informações recebidas e como as incorporam aos seus modelos mentais, os quais guiarão seus comportamentos.

Ao se tratar de estilos de aprendizagem, observa-se que o assunto tem sido tema de estudo no campo da Educação e da Psicologia cognitiva, na busca de um melhor entendimento sobre como ocorre o processo de ensino-aprendizagem e da forma pela qual os indivíduos percebem, assimilam e processam as informações. Além disso, o tema de estudo tem sido utilizado no campo da Administração, nas mais diversas organizações, como uma ferramenta que possibilita conhecer as preferências de aprendizagem das pessoas que ocupam cargos estratégicos e que participam do processo decisório das organizações.

Os estilos de aprendizagem derivam da teoria da aprendizagem experiencial, a qual define a aprendizagem como o processo pelo qual o conhecimento é criado a partir da transformação da experiência, oferecendo informações sobre o modo como as pessoas aprendem e se desenvolvem (Simelane-Mnisi \& Mji, 2015).

No campo dos estudos organizacionais, sublinha-se o estudo sobre estilos de aprendizagem desenvolvidos por Kolb (1976; 1985; 1997; 1999). Esse autor idealizou um inventário de estilos de aprendizagem com o intuito de identificar, como o nome já diz, os estilos individuais de aprendizagem, abarcando duas dimensões (ativo-reflexiva e abstrato-concreta), que deram origem a quatro estilos de aprendizagem: convergente, divergente, assimilador e acomodador, cada qual com as características que lhe são inerentes, conforme apresentado na Figura 1.

Os divergentes são capazes de refletir experiências de múltiplas perspectivas. Eles são criativos, de mente aberta, interessados em pessoas, imaginativos, emocionais, abertos ao feedback, capazes de coletar informações, ter interesses amplos e desfrutar do trabalho em grupo. Esses aprendentes desfrutam de experiências concretas e atividades reflexivas. Os assimiladores são lógicos e capazes de compreender uma ampla gama de informações. Eles estão menos interessados nas pessoas e estão mais interessados em ideias, conceitos e teorias. Esses aprendentes podem preferir palestras, ler, explorar modelos e ter tempo para conceituação abstrata e reflexão. Os convergentes podem colocar a teoria em prática e resolver problemas. Indivíduos com um estilo de aprendizagem convergente preferem lidar com tarefas técnicas e problemas, ao invés de questões sociais e interpessoais. Eles aprendem melhor através da conceituação abstrata e experimentação ativa. Os acomodadores aprendem com a experimentação ativa e experiências concretas. Esses aprendentes dependem de outros para obter informações e trabalhar em grupo para atingir seus objetivos (Kolb \& Kolb, 2005). 


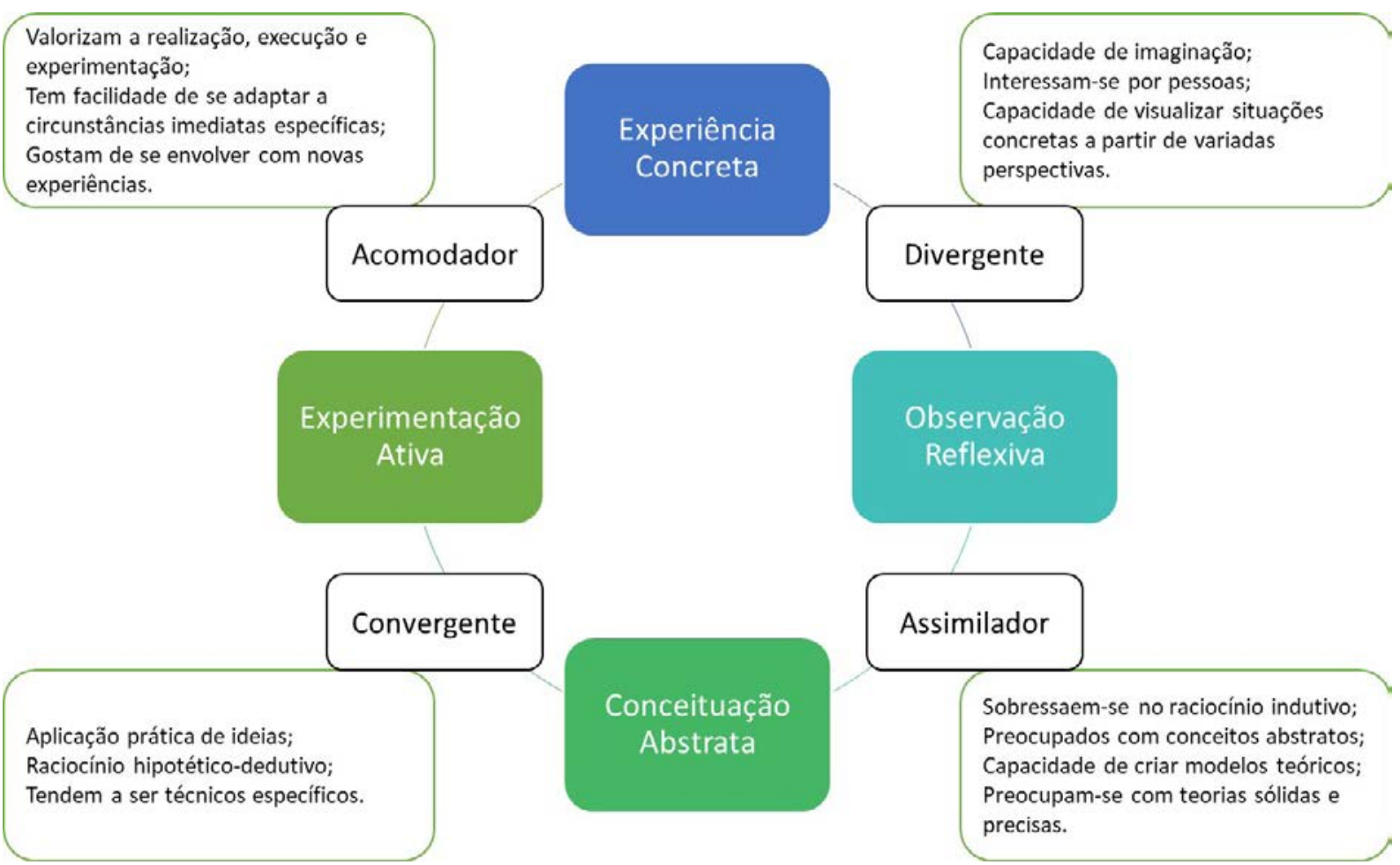

Figura 1 - Estilos de Aprendizagem e Características

Fonte: Elaborado com base em Kolb (1976; 1985; 1997; 1999); Nakayama, Binotto e Estivalete (2002).

Esses estilos de aprendizagem individual conjugam, portanto, quatro tipos de habilidades propostas no ciclo vivencial: experiência concreta (EC), observação reflexiva (OR), conceituação abstrata $(C A)$ e experimentação ativa (EA). Duas dimensões básicas podem ser consideradas no processo de aprendizagem: a primeira representa, de um lado, a experiência concreta, e, de outro, a formação de conceitos abstratos (conceituação abstrata); a segunda dimensão tem a experiência ativa, de um lado, referindo-se aos testes das implicações, e a observação e experimentação reflexiva do outro (Kolb, 1997). O Quadro 01 apresenta as características de cada uma das quatro habilidades de aprendizagem.

Quadro 01 - Características das habilidades de aprendizagem

\begin{tabular}{|l|l|}
\hline Habilidade de Aprendizagem & \multicolumn{1}{c|}{ Características } \\
\hline Experiência Concreta - EC & $\begin{array}{l}\text { Capacidade de se envolver completa, aberta e imparcialmente em novas } \\
\text { experiências. Habilidade descrita pela palavra "sentir". }\end{array}$ \\
\hline Observação Reflexiva - OR & $\begin{array}{l}\text { Capacidade de refletir sobre experiências e observá-las a partir de } \\
\text { diversas perspectivas. Habilidade descrita pela palavra "observar". }\end{array}$ \\
\hline Conceituação Abstrata - CA & $\begin{array}{l}\text { Capacidade criar conceitos que integrem suas observações em teorias } \\
\text { sólidas em termos de lógica. Habilidade descrita pela palavra "pensar". }\end{array}$ \\
\hline Experimentação Ativa - EA & $\begin{array}{l}\text { Capacidade de utilizar teorias para tomar decisões e resolver problemas. } \\
\text { Habilidade descrita pela palavra "fazer". }\end{array}$ \\
\hline
\end{tabular}

Fonte: Kolb (1997)

A primeira versão do Inventário de estilos de aprendizagem, idealizado por Kolb (1976), consiste em um questionário de autodescrição, com quatro colunas de nove itens, pelo qual os indivíduos são instruídos a ordenar, entre quatro palavras disponíveis, aquelas que melhor descrevem o seu modo de aprendizado. Cada uma das quatro palavras está relacionada a uma das quatro habilidades de aprendizagem (EC, OR, CA e EA). A partir do conhecimento das habilidades proeminentes é possível indentificar o estilo de aprendizagem do indivíduo (Manolis, Burns, Assudani \& Chinta, 2013). Vale ressaltar que existem versões revisadas por Kolb em momentos posteriores (Kolb, 1985;1999), as quais também contemplam a mensuração das habilidades de aprendizagem dispostas na versão inicial. 
Sendo assim, esse inventário propõe-se a avaliar a importância do processo de aprendizagem. Por meio dele, o modelo segundo o qual as pessoas aprendem é compreendido como um ciclo composto de quatro fases, denominado de modelo vivencial, conforme pode ser visualizado na Figura 1. Para que a aprendizagem seja efetiva, os quatro tipos de habilidades são considerados necessários. No entanto, algumas pessoas podem evidenciar características mais fortes de um determinado tipo de habilidade em relação aos outros, em virtude das diferenças e peculiaridades individuais (Kolb, 1997). A próxima seção tem por intuito a exposição conceitual de um construto possivelmente relacionado ao estilo individual de aprendizagem: a atitude empreendedora.

\subsection{Atitude Empreendedora e sua Mensuração pelo IMAE}

Primeiramente, torna-se necessário compreender o conceito de atitude quando relacionada ao empreendedorismo. A atitude, de acordo com Lopes Jr. e Souza (2005), é definida como uma disposição para responder a um objeto psicológico com algum grau de favorabilidade ou desfavorabilidade.

Relacionando atitude e empreendedorismo, Souza, Lopes, Bornia e Alves (2013) ponderam que a atitude empreendedora é uma predisposição para o comportamento empreendedor, o qual é influenciado por características do indivíduo e do meio em que está inserido. Sendo assim, ao se mensurar a atitude das pessoas, pode-se explicar o comportamento empreendedor, o qual está relacionado com a busca incessante por novas oportunidades, com a criação de algo novo e com o entendimento de como essas novas oportunidades poderão trazer resultados positivos para a organização (Dornelas, 2003).

Para Filion (1991), inovação, liderança, exposição a riscos, autoconhecimento, iniciativa, criatividade, formação de rede de relacionamento próprio e desenvolvimento de métodos de aprendizagem são características atitudinais comuns aos indivíduos empreendedores.

A atitude empreendedora, sob a perspectiva de análise alicerçada na teoria do comportamento planejado de Ajzen (1985), é definida como uma avaliação frente a um objeto de estímulo, influenciada por crenças acessíveis na memória e que guiam o comportamento correspondente (Ajzen \& Fishbein, 1977).

Nessa direção, a teoria do comportamento planejado de Ajzen (1985) parte do pressuposto de que a atitude, normas subjetivas e controle comportamental, percebidos de maneira conjunta, podem moldar comportamentos e intenções de um indivíduo.

Guiados pelo interesse em avaliar os níveis de atitude empreendedora nos indivíduos, Lopes Jr. e Souza (2005) dedicaram-se à construção de um instrumento de mensuração a partir de um estudo realizado pelo Management Systems International - MSI (1999), o qual identificou as principais características dos empreendedores de sucesso. Além das características trazidas pelo MSI - planejamento, realização e poder - esses autores adicionaram uma quarta dimensão para a atitude empreendedora: a inovação.

O instrumento resultante do estudo de Lopes Jr. e Souza (2005) obteve indicadores estatisticamente confiáveis em relação a sua construção, validação e confiabilidade, recebendo a denominação de Instrumento de mensuração da atitude empreendedora (IMAE). As dimensões desse modelo, bem como suas descrições, estão dispostas no Quadro 02.

Quadro 02 - Dimensões do IMAE

\begin{tabular}{|l|l|}
\hline \multicolumn{1}{|c|}{ Dimensão } & \multicolumn{1}{c|}{ Descrição } \\
\hline Planejamento & $\begin{array}{l}\text { Predisposição para gerenciar o empreendimento, a fim de obter informações para } \\
\text { acompanhá-lo e avaliá-lo sistematicamente. }\end{array}$ \\
\hline Realização & $\begin{array}{l}\text { Predisposição para ter iniciativas, tomar decisões, atingir objetivos, cumprir metas, } \\
\text { buscar oportunidades e aceitar riscos. }\end{array}$ \\
\hline Poder & $\begin{array}{l}\text { Predisposição para liderar, influenciar nas ações e nos resultados do empreendimento, } \\
\text { estabelecer redes sociais e desenvolver a autoconfiança. }\end{array}$ \\
\hline Inovação & $\begin{array}{l}\text { Predisposição para agir de forma inovadora e criativa, e construir diferenciais competitivos } \\
\text { e produtivos. }\end{array}$ \\
\hline
\end{tabular}

Fonte: Lopes Jr. e Souza (2005); Souza et al. (2013). 
No estudo aqui apresentado, adota-se o modelo IMAE de forma a identificar os níveis de predisposição dos servidores públicos pesquisados em relação às dimensões da atitude empreendedora. Compreendese, conforme dispõe Diefenbach (2011), que o empreendedorismo no serviço público pode contribuir para maximizar a produtividade e a efetividade na organização.

Para ampliar a compreensão sobre o tema, acrescenta-se a contribuição de Lopes Jr. e Souza (2005, p.4) de que a atitude empreendedora consiste na "predisposição aprendida, ou não, para agir de forma inovadora, autônoma, planejada e criativa, estabelecendo redes sociais".

Vale ressaltar a existência de outros modelos de mensuração relativos aos níveis individuais de empreendedorismo. Tais modelos, todavia, mensuram aspectos distintos à atitude, tais como o potencial ou orientação empreendedora (Carland, Carland\&Hoy, 1992; Inácio Junior \& Gimenez, 2004) e as competências empreendedoras do indivíduo (Lenzi, 2008). Assim, justifica-se a adoção do IMAE, neste estudo, por sua capacidade de mensuração atitudinal em relação ao empreendedorismo.

\section{Método}

Com caráter descritivo, o estudo foi conduzido pelo método survey, indicado para a coleta de dados primários quando se necessita de informações de um amplo número de pessoas (Hair, Black, Babin, Anderson \& Tatham, 2006). A população foco foi representada pelos servidores públicos lotados na unidade de gestão de pessoas (GP) de uma instituição federal de ensino localizada no estado do Rio Grande do Sul/Brasil.

A amostra da pesquisa foi não probabilística, constituída a partir da acessibilidadedos pesquisadores. A unidade de GP da instituição possui 111 servidores em exercício, regidos pela Lei n. ${ }^{\circ}$ 8.112/1990, com vínculo efetivo (concursados). Os questionários foram distribuídos a todos os servidores, exceto para os servidores que se encontravam em período de férias, afastamentos ou licenças. O retorno foi de 65 questionários, porém, devido a problemas de preenchimento, somente 53 deles foram considerados válidos para a realização das análises.

Como instrumento de coleta de dados, utilizou-se um questionário composto de três seções. A primeira contou com variáveis sociodemográficas e profissionais, tais como gênero, faixa etária e tempo de serviço na instituição. A segunda foi composta pelo Inventário de estilos de aprendizagem (Kolb, 1976), e a terceira e última seção trouxe o IMAE, de Souza e Lopez Jr. (2005). O questionário foi operacionalizado no formato impresso, e a coleta ocorreu durante o mês de março de 2017. Após a tabulação dos dados em planilhas eletrônicas, os mesmos foram analisados com o apoio do software Statistical Package for the Social Sciences (SPSS).

O Inventário de estilos de aprendizagem, na versão utilizada (Kolb, 1976), consiste em um questionário de autodescrição com nove fileiras de quatro palavras cada. Os respondentes foram solicitados à ordenálas, em cada fileira, na sequência que melhor descrevesse seu modo de aprender, utilizando a numeração de um (1) a quatro (4), sendo o menor valor atribuído à palavra que menos caracterizasse a maneira como aprende e o maior valor atribuído à palavra que melhor descrevesse a maneira como aprende. Cada uma das quatro palavras está relacionada a uma das quatro habilidades de aprendizagem (EC, OR, CA e EA). A partir da identificação das habilidades proeminentes, de acordo com as orientações do instrumento, foram identificados os estilos de aprendizagem dos pesquisados (convergente, divergente, assimilador, acomodador).

A escala IMAE, validada por Souza e Lopez Jr. (2005), é composta por 36 itens, sendo 13 na dimensão Planejamento, 9 na dimensão Realização, 8 na dimensão Poder e 6 na dimensão Inovação. Originalmente, esses autores utilizaram uma escala tipo Likert, de 10 pontos, sendo que 1 significa "nunca apresenta atitude empreendedora" e 10 indica "frequentemente possui essa atitude". No presente estudo, as respostas ao instrumento foram adaptadas para uma escala tipo Likert de 5 pontos, pois, conforme sinalizam Dalmoro e Vieira (2013), ela melhor se ajusta a respondentes com diferentes níveis de habilidade. Com a adaptação, diante dos itens, os respondentes tinham as seguintes opções de resposta: $1=$ Nunca, 2 = Raras vezes, $3=$ Às vezes, 4 = Frequentemente e 5 = Sempre. Uma vez que o instrumento foi aplicado em uma organização pública, pequenos ajustes semânticos foram necessários em seus itens, destacando-se a alteração da palavra "negócio" para "trabalho". 
Quanto à análise dos dados, o estudo compreendeu quatro etapas. Na primeira, foram realizadas análises estatísticas relacionadas às variáveis sociodemográficas e profissionais, a fim de traçar o perfil dos respondentes. Na segunda, foi identificada a configuração dos tipos de habilidades de aprendizagem (EC, OR, CA e EA) e dos estilos de aprendizagem predominantes entre os respondentes (convergente, divergente, assimilador, acomodador), em decorrência da aplicação do inventário de Kolb (1976). Na terceira, foram apurados os resultados descritivos decorrentes da aplicação do IMAE, de Souza e Lopez Jr. (2005), contemplando suas quatro dimensões: Planejamento, Realização, Poder e Inovação, sendo replicada a estrutura fatorial original do modelo proposto pelos autores. A confiabilidade dos dados foi satisfatória, uma vez que o Alfa de Cronbach foi superior a 0,7 para as quatro dimensões.

Por fim, na quarta etapa, foram realizadas análises no sentido de identificar possíveis relações entre o estilo de aprendizagem individual e a atitude empreendedora no contexto pesquisado. Para tanto, foram realizadas as seguintes análises: (i) cruzamento entre o estilo de aprendizagem individual e as médias aferidas pelo IMAE; (ii) representação da estrurura hierárquica dos fatores do IMAE para cada um dos estilos de aprendizagem individual predominantes; (iii) correlações entre as habilidades de aprendizagem e as dimensões do IMAE e; (iv) cruzamento entre as informações de perfil dos respondentes e o estilo de aprendizagem individual.

\section{Análise e Discussão dos Resultados}

Esta seção dedica-se à apresentação da análise e discussão dos resultados encontrados por meio da consecução da pesquisa, contemplando: (i) a identificação do perfil dos pesquisados; (ii) a identificação dos estilos de aprendizagem individual; (iii) as mensurações relativas à atitude empreendedora e (iv) a exposição de relações entre os estilos de aprendizagem individual e a atitude empreendedora.

\subsection{Perfil dos Pesquisados}

Para o conhecimento da amostra pesquisada, foram realizados os testes estatísticos descritivos e de frequência para as variáveis sociodemográficas e profissionais contidas nos itens 1 a 8 do instrumento de coleta de dados. Fizeram parte da amostra 53 servidores, lotados e em exercício na unidade de GP da instituição em estudo. A Tabela 01 apresenta os resultados encontrados.

Tabela 01 - Perfil dos pesquisados

\begin{tabular}{|c|c|c|c|}
\hline \multicolumn{2}{|c|}{ Gênero } & \multicolumn{2}{|c|}{ Tempo de Serviço na Instituição } \\
\hline Masculino & $22(41,5 \%)$ & Até 5 anos & $21(39,6 \%)$ \\
\hline Feminino & $31(58,5 \%)$ & Entre 6 e 10 anos & $10(18,9 \%)$ \\
\hline \multicolumn{2}{|c|}{ Faixa Etária } & Entre 11 e 15 anos & $6(11,3 \%)$ \\
\hline Entre 18 e 26 anos & $3(5,7 \%)$ & Entre 16 e 20 anos & $1(1,9 \%)$ \\
\hline Entre 27 e 35 anos & $29(54,7 \%)$ & 21 ou mais anos & $15(28,3 \%)$ \\
\hline Entre 36 e 44 anos & $4(7,5 \%)$ & \multicolumn{2}{|c|}{ Nível de Instrução (maior/completo) } \\
\hline Entre 45 e 53 anos & $6(11,3 \%)$ & Ensino Médio & $1(1,9 \%)$ \\
\hline 54 ou mais anos & $11(20,8 \%)$ & Ensino Superior (Graduação) & $12(22,6 \%)$ \\
\hline \multicolumn{2}{|c|}{ Estado Civil } & Pós-Graduação (Especialização) & $21(39,6 \%)$ \\
\hline Casado (a) ou união estável & $30(56,6 \%)$ & Pós-Graduação (Mestrado) & $17(32,1 \%)$ \\
\hline Solteiro (a) & $20(37,7 \%)$ & Pós-Graduação (Doutorado) & $2(3,8 \%)$ \\
\hline Separado (a) ou divorciado (a) & $3(5,7 \%)$ & \multicolumn{2}{|c|}{ Curso Superior } \\
\hline \multicolumn{2}{|c|}{ Categoria Funcional } & Administração & $16(30,2 \%)$ \\
\hline Docente & $1(1,9 \%)$ & Direito & $4(7,5 \%)$ \\
\hline Técnico-administrativo & $52(98,1 \%)$ & Educação Física & $4(7,5 \%)$ \\
\hline \multicolumn{2}{|c|}{ Ocupante de Cargo de Chefia } & Gestão Pública & $2(3,8 \%)$ \\
\hline Sim & $16(30,2 \%)$ & Matemática & $2(3,8 \%)$ \\
\hline \multirow[t]{3}{*}{ Não } & $37(69,8 \%)$ & Outros (1 ocorrência) & $14(26,4 \%)$ \\
\hline & & Não respondeu & $10(18,9 \%)$ \\
\hline & & Não possui & $1(1,9 \%)$ \\
\hline
\end{tabular}

Fonte: Dados da pesquisa 
Quanto ao gênero, observou-se prevalência do feminino $(58,5 \%)$ em relação ao masculino $(41,5 \%)$. No que concerne à faixa etária dos pesquisados, 5,7\% possuem entre 18 e 26 anos, 54,7\% possuem entre 27 e 35 anos, $7,5 \%$ possuem entre 36 e 44 anos, $11,3 \%$ possuem entre 45 e 53 anos e, com 54 ou mais anos de idade, somaram $20,8 \%$ dos respondentes. Houve prevalência do estado civil casado (a) ou união estável $(56,6 \%)$ entre os servidores pesquisados.

No que se refere à categoria funcional, 52 dos 53 participantes fazem parte da carreira técnicoadministrativa. Entre os pesquisados, $69,8 \%$ não exercem cargos de chefia, e o tempo de exercício na instituição variou, sobretudo entre aqueles que possuem até 5 anos de tempo de serviço $(39,6 \%)$ e aqueles com 21 ou mais anos $(28,3 \%)$. Por ser uma instituição de ensino, no que tange à formação, destacou-se o domínio de pós-graduação entre os pesquisados $(75,5 \%)$. O curso superior prevalente entre os pesquisados é o de Administração (30,2\%), seguido pelos cursos de Direito e Educação Física, ambos com 4 ocorrências (7,5\%).

\subsection{Identificação dos Estilos de Aprendizagem Individual}

Primeiramente, buscou-se identificar a configuração dos tipos de habilidades de aprendizagem (EC, OR, CA e EA) predominantes entre os servidores pesquisados. Considerando os 53 preenchimentos válidos e tendo por base a coluna cuja soma apresentou o maior valor, identificou-se um empate no tipo de habilidade de aprendizagem predominante entre a conceituação abstrata e a experimentação ativa, ambas com 15 ocorrências; correspondendo, juntas, à $56,6 \%$ do total de servidores. Na sequência, aparecem a observação reflexiva e a experiência concreta, com 8 e 7 ocorrências, respectivamente. Observou-se, ainda, 8 ocorrências de empates entre dois ou três tipos de habilidades de aprendizagem. A Tabela 02 apresenta esses dados.

Tabela 02 -Tipos de habilidades de aprendizagem predominantes entre os servidores

\begin{tabular}{l|c|c|c}
\hline Habilidade de aprendizagem & Frequência & $\%$ & $\%$ Acumulada \\
\hline Conceituação Abstrata (CA) & 15 & 28,3 & 28,3 \\
\hline Experimentação Ativa (EA) & 15 & 28,3 & 56,6 \\
\hline Observação Reflexiva (OR) & 8 & 15,1 & 71,7 \\
\hline Experiência Concreta (EC) & 7 & 13,2 & 84,9 \\
\hline OR e EA & 3 & 5,7 & 90,6 \\
\hline OR e CA & 2 & 3,8 & 94,3 \\
\hline CA e EA & 2 & 3,8 & 98,1 \\
\hline EC, OR e CA & 1 & 1,9 & 100 \\
\hline Total & 53 & 100 & \\
\hline
\end{tabular}

Fonte: Dados da pesquisa

Na sequência, para identificação dos estilos de aprendizagem predominantes, foram calculadas as pontuações médias das habilidades de aprendizagem de todos os respondentes. Os valores, em ordem hierárquica, foram os seguintes: experimentação ativa $(16,57)$, conceituação abstrata $(16,38)$, observação reflexiva $(15,02)$ e experiência ativa $(14,17)$. A Figura 2 ilustra graficamente essa composição.

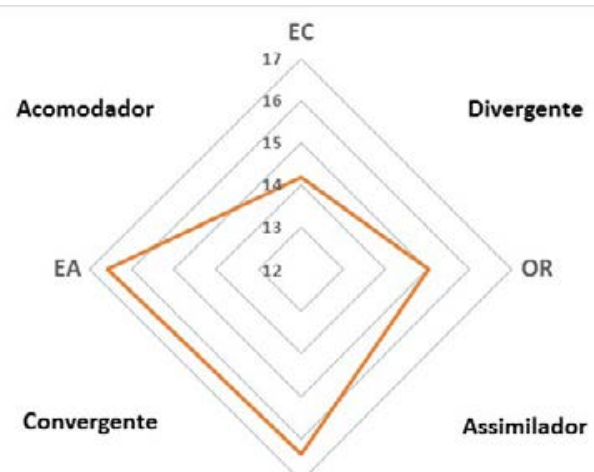

CA

Figura 02 - Estilos de aprendizagem individual predominantes entre os servidores Fonte: Elaborada pelos autores 
Observa-se, por meio da Figura 02, que o estilo predominante na amostra é o convergente. As habilidades de aprendizagem predominantes nesse estilo são a CA e a EA, relacionando-se com a forte aplicação prática de ideias. As pessoas que apresentam esse estilo se saem melhor em testes convencionais de inteligência, nos quais existem apenas uma solução ou resposta correta. Utilizando-se de raciocínio hipotético-dedutivo, o conhecimento do indivíduo convergente é canalizado para a resolução de problemas específicos. Tendem a lidar melhor com coisas do que com pessoas, tendo interesse por carreiras técnicas (Kolb, 1997). Notase a coerência desse resultado com as atividades técnicas realizadas pelos servidores públicos atuantes em unidades de gestão de pessoas, pois tais atividades envolvem a resolução de problemas específicos, que exigem soluções pontuais e, muitas vezes, disciplinadas em leis e regulamentos. $O$ indivíduo, nesse contexto, utilizará seu raciocínio hipotético-dedutivo para aplicar o conhecimento ao problema analisado.

Em segundo lugar, destaca-se o estilo assimilador como predominante. As habilidades predominantes nesse estilo são a CA e a OR, relacionando-se com a capacidade de criar modelos teóricos. Os indivíduos com essa composição de habilidades predominantes utilizam-se do raciocínio indutivo para assimilar observações e transformá-las em explicações. Estão mais preocupados com conceitos abstratos do que com pessoas. Não estão preocupados com o uso prático de uma teoria, e sim com a solidez de sua lógica. Esse estilo relaciona-se com as atividades de pesquisa e planejamento (Kolb, 1997). Esse resultado pode ser reflexo do alto índice de formação em nível de pós-graduação dos servidores públicos pesquisados (75,5\%), a qual pode impactar em preocupações mais teóricas do que práticas.

O estilo acomodador aparece na sequência de predominância. As habilidades dominantes nesse estilo são a EA e a EC, relacionando-se com a capacidade de realizar coisas. Indivíduos com esse estilo focam na execução de planos e envolvimento em novas experiências. Com maior exposição ao risco, tendem a se adaptar melhor em condições adversas. Diante de fatos novos, os acomodadores podem descartar planos ou teorias para agir. Gostam de pessoas, ainda que possam apresentar sinais de impaciência e pressão sobre subordinados. Geralmente possuem formação técnica ou prática e melhor desempenham tarefas orientadas para a ação, tais como vendas (Kolb, 1997). Percebe-se a coerência desse resultado com as atividades comportamentais gerenciadas pelos servidores públicos atuantes em unidades de gestão de pessoas, pois tais atividades envolvem a ação e o contato direto com as demais pessoas da organização.

Por fim, com a menor predominância, destaca-se o estilo divergente. Salienta-se que, na amostra pesquisada, apenas um indivíduo apresentou esse estilo de aprendizagem individual. As habilidades de aprendizagem predominantes nesse estilo são a EC e a OR. Distinguem-se pela capacidade de ver situações concretas a partir de variadas perspectivas. Curiosamente, na visão de (Kolb, 1997), gerentes de pessoal são caracterizados por esse estilo, o que não se confirmou na unidade de gestão de pessoas pesquisada.

Por meio do estudo, identificou-se que há predominância dos estilos de aprendizagem convergente, assimilador e acomodador, com 16, 14 e 13 indivíduos na amostra, respectivamente. Apenas um indivíduo apresentou o estilo divergente, e os outros 9 obtiveram estilos simultâneos na análise do instrumento.

\subsection{Mensuração da Atitude Empreendedora}

O IMAE, apresentado por Souza e Lopez Jr. (2005), possui 36 itens distribuídos em quatro dimensões (Poder, Realização, Inovação e Planejamento). Os itens do instrumento foram respondidos em escala tipo Likert de 5 pontos, possuindo as seguintes possibilidades de resposta para as afirmações: $1=$ Nunca, $2=$ Raras vezes, $3=$ Às vezes, $4=$ Frequentemente e $5=$ Sempre. A Tabela 03 apresenta estatísticas descritivas para os itens de cada uma das quatro dimensões. 
Tabela 03 - Resultados decorrentes da aplicação do IMAE

\begin{tabular}{|c|c|c|}
\hline Dimensão/Variáveis & Média & DP \\
\hline \multicolumn{3}{|l|}{ Poder - Média $=3,74-$ Alfa de Cronbach $=0,709$} \\
\hline 26. Confio na minha competência como fonte de sucesso do meu trabalho. & 4,21 & 0,717 \\
\hline 25. Considero-me o principal responsável pelo desempenho do meu trabalho. & 4,19 & 0,810 \\
\hline 10. Confio na minha capacidade de superar desafios. & 4,06 & 0,770 \\
\hline $\begin{array}{l}\text { 24. Assumo a responsabilidade pela resolução de problemas que possam prejudicar o } \\
\text { desempenho de meu trabalho. }\end{array}$ & 3,98 & 0,888 \\
\hline 35. Estimulo o espírito de equipe entre meus colegas. & 3,91 & 0,791 \\
\hline 36. Estimulo a participação dos meus colegas na busca pela solução de um problema. & 3,83 & 0,849 \\
\hline 7. Utilizo contatos pessoais para atingir meus objetivos. & 3,02 & 1,168 \\
\hline 14. Utilizo estratégias deliberadas para influenciar pessoas. & 2,72 & 0,948 \\
\hline \multicolumn{3}{|l|}{ Realização - Média = 3,65 - Alfa de Cronbach = 0,726 } \\
\hline 8. Responsabilizo-me pela conclusão dos trabalhos nos prazos estipulados. & 4,64 & 0,558 \\
\hline 13. Junto-me aos colegas nas tarefas para cumprir os prazos. & 4,28 & 0,769 \\
\hline 27. Emprego esforços extras para a conclusão de tarefas programadas. & 4,00 & 0,855 \\
\hline 20. Removo meus esforços para superar obstáculos. & 3,55 & 0,867 \\
\hline 17. Faço sacrifícios pessoais para concluir tarefas. & 3,51 & 0,993 \\
\hline $\begin{array}{l}\text { 18. Mantenho meus objetivos mesmo diante de resultados que não são satisfatórios } \\
\text { inicialmente. }\end{array}$ & 3,51 & 0,750 \\
\hline 30. Assumo riscos com intuito de superar problemas. & 3,25 & 0,959 \\
\hline 2. Exploro novas oportunidades de trabalho. & 3,09 & 0,946 \\
\hline 4. Assumo riscos para expandir meu trabalho. & 3,06 & 0,929 \\
\hline \multicolumn{3}{|l|}{ Inovação - Média = 3,60 - Alfa de Cronbach = 0,863 } \\
\hline $\begin{array}{l}\text { 21. Busco novas soluções para atender às necessidades de colegas e usuários dos } \\
\text { serviços prestados. }\end{array}$ & 4,09 & 0,597 \\
\hline 11. Busco novas maneiras de realizar tarefas. & 3,64 & 0,682 \\
\hline 28. Desenvolvo ideias novas para a solução de problemas. & 3,53 & 0,775 \\
\hline 23. Procuro criar novas ideias. & 3,51 & 0,775 \\
\hline 1. Implemento novas ideias com o objetivo de melhorar a qualidade do meu trabalho. & 3,49 & 0,608 \\
\hline 31. Crio novas rotinas, objetivando a melhoria do desempenho do meu trabalho. & 3,32 & 0,915 \\
\hline \multicolumn{3}{|l|}{ Planejamento - Média = 3,59 - Alfa de Cronbach = 0,831 } \\
\hline $\begin{array}{l}\text { 6. Adoto procedimentos para assegurar que o trabalho atenda a padrões de qualidade } \\
\text { previamente estipulados. }\end{array}$ & 4,25 & 0,585 \\
\hline 34. Calculo os riscos de novos investimentos ou novas responsabilidades. & 3,77 & 0,776 \\
\hline 33. Costumo calcular o risco envolvido nos trabalhos que executo. & 3,72 & 0,818 \\
\hline 3. Mudo de estratégia, se necessário, para alcançar uma meta. & 3,70 & 0,774 \\
\hline 32. Ajo antes de ser pressionado pelas circunstâncias. & 3,70 & 0,799 \\
\hline 16. Busco informações sobre minha área de atuação em diferentes fontes. & 3,64 & 0,834 \\
\hline $\begin{array}{l}\text { 22. Planejo as atividades do meu trabalho subdividindo tarefas de grande porte em } \\
\text { subtarefas. }\end{array}$ & 3,64 & 0,879 \\
\hline 12. Faço projeções claras para o futuro do meu trabalho. & 3,55 & 0,822 \\
\hline 19. Consulto meus registros de controle antes de tomar decisões. & 3,53 & 0,890 \\
\hline 9. Busco informações sobre possíveis oportunidades. & 3,36 & 0,857 \\
\hline 5. Defino metas de longo prazo, claras e específicas & 3,32 & 0,872 \\
\hline 15. Reviso continuamente objetivos de curto prazo. & 3,32 & 0,754 \\
\hline 29. Defino continuamente objetivos de curto prazo. & 3,19 & 0,878 \\
\hline
\end{tabular}

Fonte: Dados da pesquisa 
Observa-se que, entre os servidores pesquisados, as médias para as quatros dimensões do IMAE situaram-se entre 3 e 4, sendo a dimensão Poder a que obteve a maior média $(3,74)$, enquanto que a de Planejamento foi a menor $(3,59)$. De forma intermediária, estão as dimensões Realização e Inovação com as médias 3,65 e 3,60, respectivamente.

A dimensão Poder reconhece que a atitude empreendedora está relacionada com a predisposição para liderar, influenciar nas ações e nos resultados organizacionais, bem como o estabelecimento de redes sociais e desenvolvimento da autoconfiança (Souza e Lopez Jr., 2005). No contexto pesquisado, sobressaem-se, com as maiores médias, as variáveis relacionadas à autoconfiança dos servidores em relação à competência necessária para ter sucesso no trabalho (item 26), responsabilidade pelo desempenho (item 25) e capacidade de superar desafios (item 10). Por outro lado, com as menores médias, estão variáveis relacionadas ao estabelecimento de redes sociais e poder de influência (itens 7 e 14).

A dimensão Realização indica que a atitude empreendedora está relacionada com a capacidade de ter iniciativa, tomar decisões, atingir objetivos, cumprir metas, prospectar oportunidades e assumir riscos (Souza \& Lopez Jr., 2005). No contexto pesquisado, com as maiores médias, destacam-se as variáveis relacionadas ao cumprimento tarefas dentro de prazos estipulados (itens 8 e 13). Por outro lado, com as menores médias, estão variáveis relacionadas à assunção de riscos e busca de novas oportunidades (itens 30, 2 e 4).

De acordo com a dimensão Inovação, a atitude empreendedora está relacionada com a predisposição para agir de forma inovadora e criativa, e construir diferenciais competitivos e produtivos (Souza \& Lopez Jr., 2005). No contexto pesquisado, sobressaem-se, com as maiores médias, as variáveis relacionadas com a busca por novas soluções para tarefas cotidianas, relacionadas aos serviços prestados (itens 21 e 11). Por outro lado, com as menores médias, ainda que superiores a 3,00, estão variáveis relacionadas à criação de novas ideias que melhorem a qualidade e o desempenho do trabalho (itens 1 e 31).

Por fim, com a menor média no estudo, a dimensão Planejamento reconhece que a atitude empreendedora está relacionada com a predisposição para gerenciar o empreendimento/trabalho, a fim de obter informações para acompanhá-lo e avaliá-lo sistematicamente (Souza \& Lopez Jr., 2005). No contexto pesquisado, com as maiores médias, destacam-se as variáveis relacionadas a adoção de procedimentos para assegurar que o trabalho atenda a padrões de qualidade previamente estipulados (item 6), assim como a mensuração de riscos envolvidos no trabalho executado e em possíveis novas responsabilidades (itens 33 e 34 ). Com as menores médias, por outro lado, destacam-se variáveis relacionadas à definição e revisão de objetivos e metas de curto ou longo prazos (itens 5, 15 e 29). Esses resultados apontam, portanto, que a atitude empreendedora está mais relacionada a aspectos cotidianos referentes à execução do trabalho no contexto pesquisado.

\subsection{Relações entre os Estilos de Aprendizagem Individual e a Atitude Empreendedora}

Tendo em vista a proeminência dos estilos de aprendizagem individual convergente, assimilador e acomodador entre os servidores pesquisados $(81,13 \%)$, estes foram balizados para as análises de possíveis relações com a atitude empreendedora. Primeiramente, foi realizado um cruzamento entre o estilo de aprendizagem individual e as médias aferidas pelo IMAE. Conforme pode ser visualizado na Tabela 04, destaca-se o fato de que o estilo convergente apresentou as maiores médias em todas as dimensões do IMAE. Os estilos assimilador e acomodador apresentaram alternâncias entre as dimensões. As dimensões Poder e Realização apresentaram maior média para o estilo acomodador em relação ao estilo assimilador. As dimensões Inovação e Planejamento, por outro lado, apresentaram maior média para o estilo assimilador em relação ao estilo acomodador. 
Tabela 04 - Comparação de médias do IMAE entre os estilos de aprendizagem predominantes

\begin{tabular}{l|c|c}
\multicolumn{1}{c|}{ Dimensão IMAE } & Estilo de aprendizagem individual & Média \\
\hline Poder & Convergente & $\mathbf{3 , 8 4}$ \\
\cline { 2 - 3 } Média geral: 3,74 & Acomodador & 3,79 \\
\cline { 2 - 3 } & Assimilador & 3,61 \\
\hline Realização & Convergente & $\mathbf{3 , 8 3}$ \\
\cline { 2 - 3 } & Acomodador & 3,59 \\
\cline { 2 - 3 } & Assimilador & 3,50 \\
\hline Inovação & Convergente & $\mathbf{3 , 7 0}$ \\
\hline \multirow{2}{*}{ Média geral: 3,60} & Assimilador & 3,63 \\
\hline Planejamento & Acomodador & 3,52 \\
\cline { 2 - 3 } Média geral: 3,59 & Convergente & $\mathbf{3 , 6 9}$ \\
\cline { 2 - 3 } & Assimilador & 3,66 \\
\cline { 2 - 3 } & Acomodador & 3,50 \\
\hline
\end{tabular}

Fonte: Dados da pesquisa

Esses resultados sinalizam que o estilo de aprendizagem individual convergente, predominante entre os servidores públicos pesquisados, possui maior inclinação à atitude empreendedora nas quatro dimensões do IMAE quando comparado aos demais estilos.

A Figura 03, considerando as médias dispostas na Tabela 04, representa a estrutura hierárquica dos fatores do IMAE para cada um dos estilos de aprendizagem individual predominantes. Observa-se a mesma hierarquia para os estilos convergente e acomodador. Para esses indivíduos, na amostra pesquisada, as dimensões Poder e Realização são prevalentes na atitude empreendedora em relação às demais dimensões. Esses estilos, em comum, são característicos pela habilidade de experimentação ativa, a qual é centrada no "fazer". Sendo assim, os indivíduos possuidores desses estilos, em detrimento ao planejamento, apresentam uma predisposição para a ação prática, a qual pode estar relacionada à dimensão Realização do IMAE (Kolb, 1997; Lopes Jr. \& Souza, 2005).

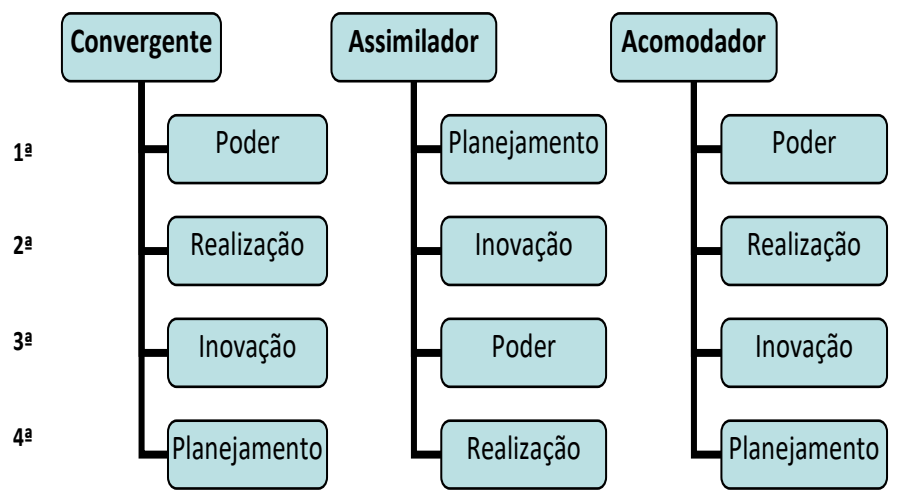

Figura 3 - Hierarquia das dimensões do IMAE para os estilos individuais de aprendizagem

Fonte: Elaborada pelos autores

Por outro lado, conforme a Figura 3, percebe-se uma hierarquia contrária para o estilo assimilador. Na amostra pesquisada, as dimensões Planejamento e Inovação são prevalentes na atitude empreendedora dos indivíduos assimiladores em relação às demais dimensões do IMAE. Esse resultado é compreensível na medida em que esse estilo é caracterizado pela capacidade de criar modelos teóricos, estando relacionado com atividades de pesquisa e planejamento (Kolb, 1997).

Tendo por base os somatórios relativos às habilidades de aprendizagem (EC, OR, CA e EA), foi possível analisar suas correlações com as dimensões do IMAE. Conforme disposto no Tabela 05, foi possível 
identificar uma correlação positiva e significativa, ainda que fraca, entre a experimentação ativa e a dimensão Realização, ratificando a análise anteriormente apresentada.

Salienta-se, ainda, a alta correlação positiva entre as dimensões Realização e Inovação do IMAE, bem como a alta correlação negativa entre as habilidades de aprendizagem CA e EC, resultado compreensível na medida em que elas se estabelecem de forma polarizada no modelo de Kolb (1997).

Tabela 05 - Matriz de correlações entre as habilidades de aprendizagem e as dimensões do IMAE

\begin{tabular}{l|c|c|c|c|c|c|c|c}
\hline & Realização & Planejamento & Poder & Inovação & EC & OR & CA & EA \\
\hline Realização & 1 &, $671^{* *}$ &, $667^{* *}$ &, $719^{* *}$ &,- 082 &,- 224 &,- 086 &, $307^{*}$ \\
\hline Planejamento & & 1 &, $654^{* *}$ &, $720^{* *}$ &,- 185 &,- 051 &, 122 &,- 013 \\
\hline Poder & & & 1 &, $614^{* *}$ &,- 082 &,- 125 &,- 067 &, 166 \\
\hline Inovação & & & & 1 &,- 164 &,- 103 &, 141 &, 070 \\
\hline EC & & & & & 1 & $-459^{* *}$ & $-736^{* *}$ & 0,14 \\
\hline OR & & & & & & 1 & $-452^{* *}$ & $-546^{* *}$ \\
\hline CA & & & & & & & 1 & $-363^{*+}$ \\
\hline EA & & & & & & & & 1 \\
\hline
\end{tabular}

** Correlações significativas ao nível de 0,05

* Correlações significativas ao nível de 0,01

Fonte: Dados da pesquisa

Por fim, buscou-se cruzar as informações de perfil dos respondentes com o estilo de aprendizagem individual, de forma a identificar alguma diferença expressiva. A Tabela 06 apresenta esses resultados.

Tabela 06 - Estilos de aprendizagem individual X perfil

\begin{tabular}{|c|c|c|c|}
\hline & Convergente (16) & Assimilador (14) & Acomodador (13) \\
\hline Gênero & $\begin{array}{l}\text { (12) feminino } \\
\text { (4) masculino }\end{array}$ & $\begin{array}{l}\text { (2) feminino } \\
\text { (12) masculino }\end{array}$ & $\begin{array}{l}\text { (11) feminino } \\
\text { (2) masculino }\end{array}$ \\
\hline Faixa Etária & $\begin{array}{l}\text { (12) Entre } 27 \text { e } 35 \text { anos } \\
\text { (2) Entre } 45 \text { e } 53 \text { anos } \\
\text { (2) } 54 \text { ou mais anos }\end{array}$ & $\begin{array}{l}\text { (9) Entre } 27 \text { e } 35 \\
\text { (1) Entre } 36 \text { e } 44 \text { anos } \\
\text { (1) Entre } 45 \text { e } 53 \text { anos } \\
\text { (3) } 54 \text { ou mais anos }\end{array}$ & $\begin{array}{l}\text { (1) Entre } 18 \text { e } 26 \\
\text { (6) Entre } 27 \text { e } 35 \\
\text { (2) Entre } 36 \text { e } 44 \text { anos } \\
\text { (2) Entre } 45 \text { e } 53 \text { anos } \\
\text { (2) } 54 \text { ou mais anos } \\
\end{array}$ \\
\hline $\begin{array}{l}\text { Tempo de } \\
\text { serviço }\end{array}$ & $\begin{array}{l}\text { (7) Até } 5 \text { anos } \\
\text { (2) Entre } 6 \text { e } 10 \text { anos } \\
\text { (3) Entre } 11 \text { e } 15 \text { anos } \\
\text { (4) } 21 \text { ou mais anos }\end{array}$ & $\begin{array}{l}\text { (5) Até } 5 \text { anos } \\
\text { (5) Entre } 6 \text { e } 10 \text { anos } \\
\text { (1) Entre } 16 \text { e } 20 \text { anos } \\
\text { (3) } 21 \text { ou mais anos }\end{array}$ & $\begin{array}{l}\text { (5) Até } 5 \text { anos } \\
\text { (3) Entre } 6 \text { e } 10 \text { anos } \\
\text { (1) Entre } 11 \text { e } 15 \text { anos } \\
\text { (4) } 21 \text { ou mais anos }\end{array}$ \\
\hline Chefia & $\begin{array}{l}\text { (8) Sim } \\
\text { (8) Não }\end{array}$ & $\begin{array}{l}\text { (2) Sim } \\
\text { (12) Não }\end{array}$ & $\begin{array}{l}\text { (4) Sim } \\
\text { (9) Não }\end{array}$ \\
\hline Estado Civil & $\begin{array}{l}\text { (9) Casado(a)/União } \\
\text { estável } \\
\text { (7) Solteiro (a) }\end{array}$ & $\begin{array}{l}\text { (6)Casado(a)/União estável } \\
\text { (6)Solteiro(a) } \\
\text { (2)Separado(a)/Divorciado (a) }\end{array}$ & $\begin{array}{l}\text { (10)Casado(a)/União estável } \\
\text { (3)Solteiro(a) }\end{array}$ \\
\hline $\begin{array}{l}\text { Nível de } \\
\text { Instrução }\end{array}$ & $\begin{array}{l}\text { (3) Ensino Superior } \\
\text { (Graduação) } \\
\text { (5) Pós-Graduação/ } \\
\text { Especialização } \\
\text { (8) Pós-Graduação } \\
\text { (Mestrado) }\end{array}$ & $\begin{array}{l}\text { (1) Ensino Médio } \\
\text { (4) Ensino Superior/ Graduação } \\
\text { (4) Pós-Graduação/ } \\
\text { Especialização } \\
\text { (3) Pós-Graduação/ Mestrado } \\
\text { (2) Pós-Graduação/ Doutorado }\end{array}$ & $\begin{array}{l}\text { (2) Ensino Superior/ } \\
\text { Graduação } \\
\text { (7) Pós-Graduação/ } \\
\text { Especialização } \\
\text { (4) Pós-Graduação/ Mestrado }\end{array}$ \\
\hline $\begin{array}{l}\text { Curso } \\
\text { superior em: }\end{array}$ & $\begin{array}{l}\text { (6) Administração } \\
\text { (1) Arquivologia } \\
\text { (1) Direito } \\
\text { (1) Educação Física } \\
\text { (1) Estudos Sociais } \\
\text { (1) Serviço Social } \\
\text { (5) Não respondeu }\end{array}$ & $\begin{array}{l}\text { (7) Administração } \\
\text { (2) Direito } \\
\text { (1) Economia } \\
\text { (1) Engenharia Elétrica } \\
\text { (1) Gestão Pública } \\
\text { (1) Psicologia } \\
\text { (1) Não possui }\end{array}$ & \begin{tabular}{|l} 
(3) Administração \\
(1) Direito \\
(1) Educação Física \\
(1) Gestão Pública \\
(1) Letras \\
(1) Matemática \\
(1) Relações Públicas \\
(4) Não respondeu
\end{tabular} \\
\hline
\end{tabular}

Fonte: Dados da pesquisa 
Em análise à Tabela 06, algumas situações podem ser destacadas. Primeiramente, no estilo com maior inclinação à atitude empreendedora, o convergente, o gênero predominante é o feminino $(75 \%)$, situação que se repete no estilo acomodador $(84,6 \%)$. Por outro lado, de forma oposta, no estilo assimilador há predominância do gênero masculino $(85,7 \%)$. Outra constatação se refere ao exercício de chefia. Enquanto o estilo convergente corresponde à $30,2 \%$ de toda a amostra, entre os chefes, esse índice corresponde à $50 \%$. Depreende-se, assim, que os ocupantes de cargos de chefia apresentam maior inclinação à atitude empreendedora. Em relação ao nível de instrução, entre aqueles que apresentam o estilo convergente, $50 \%$ possui pós-graduação em nível de mestrado. $\mathrm{Na}$ amostra total, esse índice corresponde à $32,1 \%$.

Os resultados desta pesquisa demostraram que a diversidade de estilos individuais de aprendizagem pode ser inerente e, até mesmo, profícua ao desenvolvimento do empreendedorismo nas organizações públicas. Tendo em vista que as unidades de gestão de pessoas, tais como a pesquisada, realizam atividades de naturezas diferenciadas (técnicas ou comportamentais, com ou sem atendimento ao público), torna-se adequado observar a alocação das pessoas para que essas desempenhem tarefas relacionadas ao seu estilo individual de aprendizagem e às suas inclinações empreendedoras.

\section{Considerações Finais}

Os resultados deste estudo sinalizam algumas constatações que poderão nortear os gestores públicos interessados em promover a atitude empreendedora em suas unidades de trabalho. Uma vez conhecido o estilo individual de aprendizagem, torna-se possível lotar o servidor público em setor que o compatibilize com a atitude empreendedora esperada.

$\mathrm{Na}$ amostra pesquisada, o estilo de aprendizagem preponderante foi o convergente, sendo esse qualificado por pessoas que integram teoria e prática, ou seja, que melhor se adaptam a tarefas técnicas e que buscam resolver problemas práticos. Esse resultado se mostra consonante com a composição técnicoadministrativa dos trabalhadores da unidade de GP da instituição pesquisada. Desperta-se, ainda, para as ocorrências significativas dos estilos assimilador e acomodador, ao contrário do estilo divergente, o qual foi identificado em apenas um servidor.

Neste estudo, o estilo convergente foi o que se manifestou mais inclinado à atitude empreendedora em suas quatro dimensões. Destacaram-se as maiores médias atribuídas às dimensões Poder e Realização. Essas atitudes consistem em influenciar nas ações e nos resultados do trabalho, bem como a predisposição para ter iniciativa e tomar decisões baseadas em objetivos e metas estabelecidas.

Considerando toda a amostra, a dimensão Realização obteve uma correlação positiva e significativa com a habilidade de aprendizagem experimentação ativa. Isto indica que a predisposição para tomar decisões, atingir objetivos e cumprir metas, características da atitude de realização, relaciona-se com a aptidão para aplicar teorias e conhecimentos na resolução de problemas, característica da experimentação ativa.

Por fim, os cruzamentos dos três estilos preponderantes na amostra - convergente, assimilador e acomodador - com o perfil dos respondentes, trouxeram alguns resultados que poderão orientar estudos futuros, tais como investigações acerca das relações entre gênero, nível de instrução e investidura em chefia com o estilo de aprendizagem predominante, bem como seus reflexos na atitude empreendedora.

Salienta-se que, devido à constituição de uma amostra não probabilística, os resultados do estudo não podem ser generalizados. Sugere-se, para novos estudos, o estabelecimento de amostras maiores, as quais poderão propiciar maior confiabilidade e a utilização de estatísticas mais robustas nas análises. Recomenda-se, ainda, a combinação com abordagens qualitativas de forma a complementar os resultados obtidos.

\section{Referências}

Ajzen, I., \&Fishbein, M. (1977). Attitude-behavior relations: A theoretical analysis and review of empirical research. Psychological Bulletin, 84, 888-918. 
Ajzen, I. (1985). From intentions to actions: A theory of planned behavior. In J. Kuhl \& J. Beckman (Eds.), Action-control: From cognition to behavior(pp. 11-39). Heidelberg: Springer.

Argyris, C., \& Schön, D. (1996). Organizational Learning II: Theory, Method and Pratice. USA: AddisonWesley.

Bitencourt, C., \&Souza, Y. (2003). Das Práticas de Aprendizagem à Aprendizagem Organizacional. Trabalho apresentado no vigésimo sétimo Encontro Nacional dos Programas de Pós-graduação em Administração, Atibaia, Brasil.

Carland, J. W., Carland, J. A., \&Hoy, F. S. (1992). An entrepreneurship Index: an empirical validation. Frontiers of Entrepreneurship Research, 25(3), 244-265.

Dalmoro, M., \& Vieira, K. M. (2013). Dilemas na construção de escalas Tipo Likert: o número de itens e a disposição influenciam nos resultados? Revista Gestão Organizacional. 6(3), 161-174.

Diefenbach, F. E. (2011). Entrepreneurship in the public sector. When middle managers create public value. Wiesbaden: Springer gabler.

Dornelas, J. C. A. (2003). Empreendedorismo corporativo: Como ser empreendedor, inovar e se diferenciar na sua empresa. Rio de Janeiro: Campus.

Estivalete, V. F. B. (2007). O processo de aprendizagem em redes horizontais do elo varejista do agronegócio: do nível individual ao interorganizacional(Tese Doutorado, Universidade Federal do Rio Grande do Sul, Brasil). Recuperado de http://hdl.handle.net/10183/10031

Estivalete, V. F. B., Löbler, M. L., \& Pedrozo, E. Á. (2006). Repensando o processo de aprendizagem organizacional no agronegócio: um estudo de caso realizado numa cooperativa destaque em qualidade no RS. Revista de Administração Contemporânea, 10(2), 157-178.

Feger, J. E., Fischer, A., \& dos Santos Nodari, T. M. (2010). Características empreendedoras de gestores públicos municipais: Uma análise comparativa entre secretários e servidores. Revista de Administração, Contabilidade e Economia, 8(2), 215-238.

Filion, L. J. (1991). O planejamento de seu sistema de aprendizagem empresarial: Identifique uma visão e avalie o seu sistema de relações. Revista de Administração de Empresas, 31(3), 63-72.

Goodsell, C. T. (2003). The case for bureaucracy: A public administration polemic (4th ed.). Washington, DC: CQ Press.

Hair, J. F., Jr, Black, W. C; Babin, B. J; Anderson, R. E., \& Tatham, R. L. (2006). Multivariate Data Analysis (6th ed.). Upper Saddle River, NJ: Pearson Prentice Hall.

Hayes, J., \& Allinson, C. (1998). Cognitive Style and the Theory and Practice of Individual and Collective Learning in Organizations. Human Relations, 51(7), 847-871.

Inácio, E., Jr,\& Gimenez, F. A. P. (2004). Potencial empreendedor: Um instrumento para mensuração. Revista de Negócios, 9(2), 107-116.

Jong, J. P. J., Parker, S. K., Wennekers, S., \& Wu, C. (2015). Entrepreneurial behavior in organizations: Does job design matter? Entrepreneurship Teory and Practice, 39, 981-995.

Kim, D. H. (1993). The link between Individual and Organizational Learning. Sloan Management Review, 35(1), 37-50.

Kolb, D. (1976). Learning style inventory: Technical manual. Boston, MA: The McBer and Company.

Kolb, D. (1985). Learning style inventory[Revised Edition]. Boston, MA: Hay Group, Hay Resources Direct.

Kolb, D. (1999). Learning Style Inventory [Version 3: TRG Hay/McBer]. Boston, MA: Training Resources Group.

Kolb, D. (1997). A gestão e o Processo de Aprendizagem. In K. Starkey, Como as organizações aprendem: relatos dos sucessos das grandes empresas. São Paulo: Futura. 
Kolb, A. Y., \& Kolb, D. A. (2005). Learning styles and learning spaces: Enhancing experiential learning in higher education. Academy of management learning \& education, 4(2), 193-212.

Lenzi, F. C. (2008). Os empreendedores corporativos nas empresas de grande porte: um estudo da associação entre tipos psicológicos e competências empreendedoras (Tese de doutorado, Universidade de São Paulo, São Paulo, RJ, Brasil).

Lopes, G. S., Jr., \& Souza, E. C. L. (2005). Atitude empreendedora em proprietários-gerentes de pequenas empresas. Construção de um instrumento de medida. Revista Eletrônica de Administração, 11(6), $1-21$.

Management Systems International. (1999). Treinamento empresarial e fortalecimento do desempenho empresarial [Relatório Final de Pesquisa]. Boston: MSI.

Manolis, C., Burns, D. J., Assudani, R., \& Chinta, R. (2013). Assessing experiential learning styles: A methodological reconstruction and validation of the Kolb Learning Style Inventory. Learning and individual differences, 23, 44-52.

Nakayama, M. K., Binotto, E., \& Estivalete, V. F. B. (2002). Os Estilos de Aprendizagem Gerencial facilitam a Aprendizagem Individual, Coletiva e Organizacional? FACE 13(2), 311-327.

Simelane-Mnisi, S., \& Mji, A. (2015). Establishing the Reliability and Validity of the Kolb Learning Style Inventory: A South African Perspective.International Journal of Educational Sciences, 11(3), 312-319.

Souza, E. C. L., Lopes, G. S., Jr, Bornia, A. C., \& Alves, L. R. (2013). Atitude empreendedora: Validação de um instrumento de medida com base no modelo de resposta gradual da Teoria de Resposta ao Item. Revista de Administração Mackenzie, 14(5), 230-251.

Tinoco, J. P. V. (2012). Empresas públicas de TIC: Proposta de um modelo analítico para auxiliar a sua gestão com empreendedorismo público e alianças estratégicas (Tese de doutorado, Pontifícia Universidade Católica do Rio de Janeiro, Rio de Janeiro, RJ, Brasil).

Townsend, W. (2013). Innovation and the perception of risk in the public sector. The International Journal of Organizational Innovation, 5(3), 21-34.

Valadares, J., \& Emmendoerfer, M. (2015). A Incorporação do empreendedorismo no setor público: reflexões baseadas no contexto brasileiro. Revista de Ciências da Administração, 1(1), 82-98.

Windrum, P. (2008). Innovation and entrepreneurship in public services. In P. Windrum \& P. Koch (Eds.), Innovation in public sector services: Entrepreneurship, creativity and management (pp. 3-20). Northampton, MA: Edward Elgar.

Submetido em: 08/03/2018

Aprovado em: 04/02/2019 